\title{
Healthy life expectancy: evaluation of global indicator of change in population health
}

\author{
Jean Marie Robine, Karen Ritchie
}

Abstract
Objective-To review and evaluate the usefulness of healthy life expectancy as a global indicator of changes in a population's health.

Design-Review of all known studies to date from the United States, mainland Europe, Canada, and the United Kingdom that have used Sullivan's method of calculating disability free life expectancy.

Main outcome measures-Life expectancy and disability free life expectancy.

Results-Over the past decade the average healthy life expectancy was 60 years for men and 64 for women, with the proportion of years of disability ranging from $11 \%$ to $21 \%$ in men and from $14 \%$ to $24 \%$ in women. At the age of 65 men could expect eight years of disability free life and women 10, with the life expectancy being respectively 14 and 19 years. The difference between the wealthiest and poorest income quintiles was 6.3 years in life expectancy and 14.3 in disability free life expectancy for men and 2.8 and 7.6 respectively for women. These results suggest that disparities in health are greater between social groups than between the sexes. Diseases affect mortality and morbidity differently. The order of importance for affecting life expectancy was circulatory disease, cancer, and accidents and for disability free life expectancy, circulatory disease, locomotor disorders, and respiratory disorders.

Conclusions - Healthy life expectancy is a valuable index for the appreciation of changes in both the physical and the mental health states of the general population, for allocating resources, and for measuring the success of political programmes. Future calculations should also take into account the probability of recovery and thus extend the applicability of the indicator to populations in poor health rather than focusing on the well population.

BMF 1991;302:457-60
Introduction

Healthy life expectancy is an index of a population's state of health derived from estimates of mortality and disability, esentially addressing the question of whether observed increases in life expectancy are also accompanied by decreases in morbidity. In other words, are the additional years spent in good health or in a prolonged state of illness and dependency? The question is obviously important both for the understanding of changes in the state of health of a given population and for the formulation of government policies directed at the provision of services.

Interest in the relation between mortality and morbidity grew out of speculation about the effects of the unpredicted drop in mortality observed in elderly people over the past 15 years. A fundamental question posed by both demographers and epidemiologists was whether this drop was prejudicial to the quality of life-for example, would people who had not died of cardiovascular disease live on in a state of chronic ill health?!

Assumptions from first principles about the effects on a population's health of the decline in mortality reflect differing hypotheses as to its cause. Fries, for example, has proposed that the decrease in the incidence of disease due to improvements in the preventive aspects of health care has had the effect of delaying the onset of disability, so people may expect to live longer in a state of good health. ${ }^{23}$ This theory has subsequently led to what Fries refers to as a "compression of morbidity" based on a hypothetical ceiling value of life expectancy.

More pessimistically, Kramer and Gruenberg have suggested that the fall in mortality has not been accompanied by a decrease in morbidity but is rather a result of the increase in the life expectancy of people with poor health. ${ }^{45}$ Kramer thus predicts increasingly poor health in populations and a subsequent "pandemic of mental disorders and associated chronic diseases."4 Others suggest that both factors have contributed to the decline in mortality, resulting in an increase in the number of people in poor health but a decrease in the prevalence of more severe disorders.

The notion of healthy life expectancy may help to clarify this debate. Early work on this subject focused on disability free life expectancy, the prevalence of disability being a comparatively easy health statistic to obtain in most developed countries. If disability free life expectancy increases at a slower rate than life expectancy a pandemic of disabilities might be expected; if it increases at a similar rate there would be no change; and if the increase is more rapid Fries's theory would be confirmed. These three possibilities are illustrated by the different relative shifts in the survival curve of the mortality-disability-morbidity model proposed by the World Health Organisation (figure). ${ }^{6}$

Female survival curves in United States, 1980: mortality and hypothetical morbidity and disability. ${ }^{6} 0^{\circ}$ and $e_{6}^{\circ} 0$ are number of years of autonomous life expected at birth and at age 60 respectively. $M_{5}^{\circ} \circ$ is age at which $50 \%$ of females could expect to survive without loss of autonomy 
Calculation of healthy life expectancy

The concept of healthy life expectancy was first elaborated by Sanders in $1964,{ }^{7}$ but it was not until the early 1970s that Sullivan proposed a simple method for estimating life expectancy as a function of disability. ${ }^{8}$ This calculation used institutionalisation rates provided by census data and the prevalences of long term and short term restrictions in activity (derived from national health studies) as qualifiers of the years lived at different ages. The total number of years lived by the population between given ages are calculated from a mortality table and the number of years without disability is deduced from prevalences from cross sectional health data. The number of years spent without disability is thus estimated and accumulated from a starting point and then divided by the number of survivors at that age, thus giving an estimate of disability free life expectancy at a given age.

Further calculations were made for the United States in 1980 by Colvez, who found that between 1966 and 1976 gains in life expectancy seemed to be entirely lost in increased disability (unpublished data), a finding that has subsequently led to a series of studies of healthy life expectancy in Europe, the United States, and Canada that used Sullivan's methods and data from cross sectional health studies.

\section{Disability free life expectancy in Western countries}

Since the appearance of the first calculations published in 1969 by the United States Department of Health, Education, and Welfare ${ }^{9}$ a series of estimates of disability free life expectancy by Sullivan's method have appeared for the United States, ${ }^{10}$ Canada, ${ }^{11}$ Quebec, ${ }^{1213}$ New Brunswick, ${ }^{14}$ and France. ${ }^{15}$ Calculations, as yet unpublished, have also been made for The Netherlands by Van Ginneken et al (The Netherlands Institute of Preventive Health Care), for Denmark by Rasmussen (Danish Institute for Clinical Epidemiology), and for Australia by Smith (Australian Institute of Health); furthermore, calculations have recently been repeated for Canada by Wilkins and Adams (Statistics Canada, Canadian Centre for Health Information). Bebbington and Crimmins et al recently published consecutive calculations, ${ }^{16}{ }^{17}$ thus permitting an appreciation of the evolution of disability free life

TABLE I-Recent regional values by sex of life expectancy $(L E)$ and disability free life expectancy $(D F L E)$ in years, with disability free life expectancy as percentage of life expectancy

\begin{tabular}{|c|c|c|c|c|c|c|}
\hline \multirow[b]{2}{*}{ Study, year } & \multicolumn{3}{|c|}{ Men } & \multicolumn{3}{|c|}{ Women } \\
\hline & LE & DFLE & DFLE/LE (\%) & LE & DFLE & DFLE/LE (\%) \\
\hline \multicolumn{7}{|l|}{ New Brunswick, late } \\
\hline $1970 \mathrm{~s}^{14}$ & $70 \cdot 0$ & $56 \cdot 7$ & $81 \cdot 0$ & $78 \cdot 1$ & $61 \cdot 1$ & $78 \cdot 2$ \\
\hline United States, $1980^{17}$ & $70 \cdot 1$ & $55 \cdot 5$ & $79 \cdot 2$ & $77 \cdot 6$ & $60 \cdot 4$ & $77 \cdot 8$ \\
\hline France, $1982^{15}$ & $70 \cdot 7$ & $61 \cdot 9$ & $87 \cdot 6$ & $78 \cdot 9$ & $67 \cdot 2$ & $85 \cdot 2$ \\
\hline The Netherlands, 1981-5* & $72 \cdot 8$ & $58 \cdot 8$ & $80 \cdot 8$ & $79 \cdot 5$ & $60 \cdot 7$ & $76 \cdot 4$ \\
\hline England and Wales, $1985^{16}$ & $71 \cdot 8$ & $58 \cdot 7$ & $81 \cdot 8$ & $77 \cdot 7$ & $61 \cdot 5$ & $79 \cdot 2$ \\
\hline Canada, 1986* & $73 \cdot 0$ & $61 \cdot 3$ & $84 \cdot 0$ & $79 \cdot 8$ & $64 \cdot 9$ & $81 \cdot 3$ \\
\hline Quebec, $1987^{13}$ & $72 \cdot 1$ & $64 \cdot 0$ & $88 \cdot 8$ & $79 \cdot 5$ & $68 \cdot 7$ & $86 \cdot 4$ \\
\hline
\end{tabular}

^Unpublished data (see text).

TABLE II - Recent regional values by sex of life expectancy $(L E)$ and disability free life expectancy $(D F L E)$ in years at age 65, with disability free life expectancy as percentage of life expectancy

\begin{tabular}{|c|c|c|c|c|c|c|}
\hline \multirow[b]{2}{*}{ Study, year } & \multicolumn{3}{|c|}{ Men } & \multicolumn{3}{|c|}{ Women } \\
\hline & LE & DFLE & DFLE/LE (\%) & $\mathrm{LE}$ & DFLE & DFLE/LE (\%) \\
\hline \multicolumn{7}{|l|}{ New Brunswick, late } \\
\hline $1970 \mathrm{~s}^{14}$ & $14 \cdot 5$ & $6 \cdot 7$ & $46 \cdot 2$ & $18 \cdot 6$ & $10 \cdot 1$ & $54 \cdot 3$ \\
\hline United States, $1980^{17}$ & $14 \cdot 2$ & $6 \cdot 6$ & $46 \cdot 5$ & $18 \cdot 4$ & 8.9 & $48 \cdot 4$ \\
\hline France, $1982^{15}$ & $14 \cdot 3$ & $9 \cdot 1$ & $63 \cdot 6$ & 18.5 & $9 \cdot 9$ & $53 \cdot 5$ \\
\hline The Netherlands, $1981-5 *$ & $14 \cdot 0$ & $7 \cdot 9$ & $56 \cdot 4$ & $18 \cdot 6$ & $8 \cdot 9$ & $47 \cdot 9$ \\
\hline England and Wales, $1985^{16}$ & $13 \cdot 4$ & $7 \cdot 7$ & $57 \cdot 5$ & $17 \cdot 5$ & $8 \cdot 9$ & $50 \cdot 9$ \\
\hline Canada, $1986^{\star}$ & 14.9 & $8 \cdot 1$ & $54 \cdot 4$ & $19 \cdot 2$ & $9 \cdot 4$ & $49 \cdot 0$ \\
\hline Quebec, $1987^{13}$ & $14 \cdot 2$ & $10 \cdot 6$ & $74 \cdot 6$ & $18 \cdot 9$ & $13 \cdot 2$ & $69 \cdot 8$ \\
\hline Australia, 1988 & $14 \cdot 8$ & $10 \cdot 8$ & $73 \cdot 0$ & $18 \cdot 7$ & $12 \cdot 1$ & $64 \cdot 7$ \\
\hline
\end{tabular}

* Unpublished data (see text). expectancy in the United Kingdom and United States over 10 years. Calculations have also been made for Japan from 1965 to $1979,{ }^{18}$ but the methods were not specified and so we were unable to include the results in this review.

SEX

The results of the most recent studies currently available estimate disability free life expectancy to be around 60 years (range 56-64 years) for men and around 64 years (range 60-69 years) for women (table I). Although disability free life expectancy, like life expectancy, remains higher in women, all studies suggest that men spend a marginally smaller proportion of their life in poor health (from $79 \%$ to $89 \%$ ) than women do (from $76 \%$ to $86 \%$ ). Therefore, though women may live longer, a slightly greater proportion of their life is probably spent disabled. All calculations of disability free life expectancy in England and elsewhere since Sullivan have confirmed this finding.

AGE

At age 65 disability free life expectancy is around eight years for men and 10 for women, whereas life expectancy is respectively around 14 and 19 years (table II). The importance of the gap between the sexes in disability free life expectancy seems to diminish with age.

\section{SOCIOECONOMIC GROUP}

The gap increases appreciably between the sexes when socioeconomic group is considered, an observation that further highlights health inequities, particularly for women, in whom no disparities are observed when life expectancy is considered alone. The difference in disability free life expectancy between the richest and poorest fifth of the population is 14 years for men and eight for women (table III). Thus

TABLE III-Differences in life expectancy ( $L E)$ and disability free life expectancy (DFLE) in years between wealthiest and poorest income quintiles in Canada

\begin{tabular}{|c|c|c|c|}
\hline & LE & DFLE & DFLE/LE $(\%)$ \\
\hline \multicolumn{4}{|c|}{ Men } \\
\hline Poorest fifth & $67 \cdot 1$ & $50 \cdot 0$ & $74 \cdot 5$ \\
\hline Richest fifth & $73 \cdot 4$ & $64 \cdot 3$ & $87 \cdot 6$ \\
\hline Difference & $6 \cdot 3$ & $14 \cdot 3$ & - \\
\hline \multicolumn{4}{|c|}{ Women } \\
\hline Poorest fifth & 76.6 & $59 \cdot 9$ & $78 \cdot 2$ \\
\hline Richest fifth & $79 \cdot 4$ & $67 \cdot 5$ & $85 \cdot 0$ \\
\hline Difference & $2 \cdot 8$ & $7 \cdot 6$ & - \\
\hline
\end{tabular}

wealthier people not only live longer but they also spend a significantly smaller proportion of their life disabled. Calculations of disability free life expectancy suggest that health disparities are greater between social groups than between the sexes.

\section{DISEASE}

The calculation of theoretical gains in disability free life expectancy when different diseases are eliminated permits the construction of a hierarchy of diseases in terms of the extent to which their suppression increases both life expectancy and healthy life expectancy. The ranking of different diseases is not the same for mortality and morbidity. ${ }^{1012}$ The order of importance in terms of effect on life expectancy is disorders of the circulatory system, malignant neoplasms, and accidents whereas for healthy life expectancy it is disorders of the circulatory system, locomotor disorders, and respiratory disorders (table IV). Thus a health programme that led to the elimination of malignant tumours would be expected to increase life expectancy for the general population by 1.7 years and years free of disability by 0.3 years. On the other hand, the elimination of locomotor disorders would give a gain of 
TABLE IV-Ranked years gained in life expectancy ( $L E)$ and disability free life expectancy (DFLE) and their total when different causes of ill health are eliminated. Data are for both sexes in United States, $1974^{\prime \prime}$

\begin{tabular}{|c|c|c|c|c|c|c|}
\hline \multirow[b]{2}{*}{ Cause } & \multicolumn{2}{|c|}{ DFLE } & \multicolumn{2}{|l|}{ LE } & \multicolumn{2}{|l|}{ Total } \\
\hline & Years gained & Rank & Years gained & Rank & Years gained & Rank \\
\hline Circulatory diseases & $4 \cdot 2$ & 2 & $4 \cdot 1$ & 1 & $8 \cdot 3$ & 1 \\
\hline Locomotor disorders & $5 \cdot 1$ & 1 & $0 \cdot 2$ & 7 & $5 \cdot 3$ & 2 \\
\hline Respiratory disorders & $2 \cdot 2$ & 3 & 0.5 & 5 & $2 \cdot 7$ & 3 \\
\hline Malignant neoplasms & $0 \cdot 3$ & 8 & $1 \cdot 7$ & 2 & $2 \cdot 0$ & 4 \\
\hline Injuries & $0 \cdot 4$ & 7 & $1 \cdot 5$ & 3 & 1.9 & 5 \\
\hline Visual and hearing impairments & $1 \cdot 1$ & 4 & - & - & $1 \cdot 1$ & 6 \\
\hline Mental disorders & $0 \cdot 6$ & 6 & 0.4 & 6 & $1 \cdot 0$ & 7 \\
\hline Diabetes & 0.7 & 5 & $0 \cdot 2$ & 7 & 0.9 & 8 \\
\hline Perinatal mortality & - & - & $0 \cdot 7$ & 4 & $0 \cdot 7$ & 9 \\
\hline Infectious diseases & $0 \cdot 2$ & 9 & $0 \cdot 1$ & 9 & $0 \cdot 3$ & 10 \\
\hline
\end{tabular}

$0 \cdot 2$ years in life expectancy, but $5 \cdot 1$ years free of disability. At present the evaluation of health intervention programmes is based principally on changes in mortality.

This example shows how such calculations may provide a useful alternative criterion for the setting of health objectives - that is, using the increase in years without disability as opposed to decreased mortality. Modelling life expectancy and disability free life expectancy as a function of specific diseases is, however, still mainly of theoretical interest as more realistic calculations would need to take into account the complex interrelation between risk factors and morbidity.

TIME

Few attempts have been made to calculate chronological series of disability free life expectancy with strictly identical methods and comparable data. In the United States from 1958 to 1966 the change in disability free life expectancy was slight, with a simultaneous stagnation in life expectancy. ${ }^{9}$ With an expanded definition of disability the reverse was the case from 1966 to 1976. This finding is supported by more recent calculations, which show that life expectancy at birth rose by three years between 1970 and 1980 while disability free life expectancy stayed virtually the same. ${ }^{17}$ The proportion of years spent without disability has thus fallen in the United States (table V).

In England and Wales from 1976 to 1985 disability free life expectancy increased more slowly than life expectancy for men, such that the proportion of years spent without disability within the total life expectancy fell from $83 \cdot 1 \%$ to $81 \cdot 8 \%$ (table V). For women, on the

TABLE $\mathrm{v}-L$ ife expectancy ( $L E)$ and disability free life expectancy $(D F L E)$ in years with time and by sex in United States and England and Wales, with disability free life expectancy as percentage of life expectancy

\begin{tabular}{|c|c|c|c|c|c|c|}
\hline \multirow[b]{2}{*}{ Year } & \multicolumn{3}{|c|}{ Men } & \multicolumn{3}{|c|}{ Women } \\
\hline & LE & DFLE & DFLE/LE (\%) & LE & DFLE & DFLE/LE (\%) \\
\hline \multicolumn{7}{|c|}{ United States } \\
\hline 1970 & $67 \cdot 0$ & $54 \cdot 8$ & 81.8 & $74 \cdot 6$ & $60 \cdot 4$ & $81 \cdot 0$ \\
\hline 1980 & $70 \cdot 1$ & 55.5 & $79 \cdot 2$ & $77 \cdot 6$ & $60 \cdot 4$ & $77 \cdot 8$ \\
\hline \multicolumn{7}{|c|}{ England and Wales ${ }^{\prime s}$} \\
\hline 1976 & $70 \cdot 0$ & $58 \cdot 2$ & $83 \cdot 1$ & $76 \cdot 1$ & $61 \cdot 7$ & $81 \cdot 1$ \\
\hline 1981 & $71 \cdot 1$ & $58 \cdot 5$ & $82 \cdot 3$ & $77 \cdot 1$ & $60 \cdot 6$ & $78 \cdot 6$ \\
\hline 1985 & $71 \cdot 8$ & $58 \cdot 7$ & $81 \cdot 8$ & $77 \cdot 7$ & $61 \cdot 5$ & $79 \cdot 2$ \\
\hline
\end{tabular}

other hand, disability free life expectancy stagnated while life expectancy increased by 1.6 years so that the proportion of years spent without disability fell even further from $81 \cdot 1 \%$ to $79 \cdot 2 \%$. Together these results suggest a significantly slower growth (if any) in disability free life expectancy than life expectancy, thus supporting the pandemic theory.

Extreme care should be taken in interpreting the chronological series presently available. ${ }^{17}$ Sullivan's method, which combines mortality quotients (period data) with observed disability prevalence (cohort data, which are a function of the unique history of each generation), provides only an estimation of the value being studied, with unknown precision. Indeed, Sullivan estimated the prevalence at each age for a period (such as a year) by the prevalence observed in each living generation. To constitute a period index capable of attributing a global morbidity characteristic to a given period, disability free life expectancy should be derived only from a combination of period data.

The incidences of entry into disability and recovery are difficult to observe but the probability of survival without disability for both disabled and healthy groups at the beginning of the observation period (such as the beginning of the year) should be easier to measure.

Experimental calculations with these kinds of data have already been made for people aged over 65 in Massachussetts ${ }^{1920}$ and upper Normandy. ${ }^{21}$ The upper Normandy study suggests that the additional years of disability observed in women may be explained by the survival differential in favour of women which persists beyond the acquisition of the incapacity, ${ }^{21}$ a hypothesis reinforced by Manton's study of the incidence of disability in the United States. ${ }^{22}$

\section{Current problems and future directions}

Disability free life expectancy, as opposed to simple mortality statistics, is potentially useful as a basis both for international comparisons of health state and for allocating health resources. If the principal objective of social and health systems is not only to prolong life but also to maintain its quality in terms of autonomy and social functioning for as long as possible ${ }^{6}$ then healthy life expectancy comes close in theory to being an ideal indicator for monitoring the realisation of health objectives. ${ }^{23}$ However, several difficulties in calculating disability free life expectancy remain. The most compelling is the question of the reliability of measures. Though there has been considerable consistency between studies about the method used to calculate disability free life expectancy, there remain large differences in defining and measuring disability. As the standardisation of physical disability measures has been largely realised in the past 15 years with the development of the concepts of survival roles, ${ }^{2425}$ activities of daily living, ${ }^{26}$ instrumental activities of daily living, ${ }^{27}$ and the differentiation of the notions of aptitude and performance ${ }^{28}$ more reliable instruments for the measurement of physical incapacity are now available.

Attempts to develop other measures of healthy life expectancy - notably, life expectancy without mental disability-raise once again the problem of reliable algorithms that permit intercultural comparisons. In particular, the question of whether the calculation of life expectancy without cognitive deterioration can be accurately estimated is of increasing interest, given the public health problems raised by the predicted increase in the prevalence of senile dementia. Such a measure would be useful not only for determining whether different age groups show modifications over time in dementia free life expectancy but also for examining changes in the relation between dementia and physical disability, in planning appropriate health care, and in testing aetiological hypotheses on dementia. For example, do the relatives of people with senile dementia show the same patterns of dementia free life expectancy as the general population? Early evidence suggests that they do not, ${ }^{29}$ and that there may be significant differences between the sexes. The value of these findings is, however, presently limited by the lack of data on dementia free life expectancy in the general population.

Current attempts to calculate dementia free life expectancy are handicapped not only by confusion in 
the definition of cognitive deterioration, often falsely used interchangeably with dementia, but also by the limitations of current screening methods..$^{30}$ Though the calculation of life expectancy free of irreversible cognitive deterioration would be a useful first step, the question of appropriate measures and diagnostic criteria remains a problem to be resolved, particularly if crosscultural comparisons are envisaged. An international network with representatives from eight member countries (Australia, Canada, Denmark, France, The Netherlands, the United Kingdom, United States, and Switzerland) has recently been established under the auspices of the Institut National de la Santé et de la Recherche Médicale in France to deal with this and other problems relating to the development of standardised international measures of healthy life expectancy, both physical and mental.

An important point raised by the international network is the notion of reversibility or permanence of ill health (especially disability). This question has not been properly examined to date because of the common use of Sullivan's method, which side steps the issue by directly observing prevalence (in itself a function of duration of ill health). Future calculations with period data could, however, take up this problem.

In the first instance the average duration of life up to the onset of disability could be calculated by using the probabilities of survival without disability, initially for non-disabled people alone. Such an indicator, which totally neglects disabled people, would thus be largely examining preventive health actions. Changes could be interpreted as reflecting fluctuations in the onset of disability hence the efficacy of preventive health programmes. This is clearly a useful application, but the indicator is limited, firstly, in that it inherently assumes that the disability will be permanent and, secondly, in that it focuses on factors related to good health and so applies only to the well population.

A further step would be to calculate additionally the total average duration of life without disability combining the probabilities of survival without disability for people born not disabled with that of subjects born disabled. Change in the arithmetic difference between the two average durations (total average duration of life without disability minus average duration of life up to the onset of the first period of disability) could then be used to describe the relative effectiveness of rehabilitation and therapeutic intervention programmes. In this way an indicator relevant to ill populations may also be derived. With indicators applicable to both healthy and non-healthy people the ethical dilemma of allocating healthy resources only to the well population will be overcome.

\section{Conclusions}

Although the well established overall trend in the general population is of diminishing mortality, increases may occasionally be observed for various reasons. Without validated explanatory hypotheses on changes in life expectancy in present demographic projections and a consensus on its relation to disability, the calculation of chronological series of disability free life expectancy seems to be useful in verifying different theories on the evolution of health states and in forecasting the consequences of a lowering of mortality on the functional health state of particular populations. Estimates of health state under different conditions relating to the evolution of disability (as has already been done for mortality) and more accurate projections of a population's health and resource needs should therefore be possible. Current difficulties in calculating healthy life expectancy as a population indicator relate primarily to a lack of consensus on definitions of health, morbidity, and disability and on the standardisation of calculation procedures. A further limitation lies in the restriction of present calculations to the description of healthy populations. The inclusion of probability of recovery in calculating healthy life expectancy would extend its application to ill populations and hence provide a measure of the efficacy of rehabilitation programmes. It is hoped that the newly constituted international network for the observation of healthy life expectancy will shortly be able to provide guidelines for standardisation of methods to permit crosscultural and intracultural comparisons of changes in state of health.

1 Fuch VR. "Though much is taken": reflections on aging, health, and medica are. Milbank Memorial Fund Quarterly; Health and Society 1984;62:143-65. 2 Fries JF. Aging, natural death, and the compression of morbidity. $N$ Engl Med 1980;303:130-5.

3 Fries JF. Compression of morbidity: near or far? The Milbank Quarterly 1989;67:208-32.

$4 \mathrm{Kramer} M$. The rising pandemic of mental disorders and associated chronic diseases and disabilities. Acta Psychiatr Scand 1980;62:282-97.

5 Gruenberg EM. The failures of success. Milbank Memorial Fund Quarterly; Health and Society 1977;55:3-24.

6 World Health Organisation. The uses of epidemiology in the study of the elderly: report of a WHO scientific group on the epidemiology of aging. Tech Rep Ser 1984:706.

7 Sanders BS. Measuring community health levels. Am f Public Health 1964;54:1063-70.

8 Sullivan DF. A single index of mortality and morbidity. Health Services and Mental Health Administration (HSMHA) Health Reports 1971;86:347-54.

9 United States Department of Health, Education, and Welfare. Toward a social report. Washington, DC: US Government Printing Office, 1969

10 Colvez A, Blanchet $M$. Potential gains in life expectancy free of disability: a tool for health planning. Int $\mathcal{F}$ Epidemiol 1983;12:224-9.

11 Wilkins R, Adams OB. Health expectancy in Canada, late 1970s: demographic, regional, and social dimensions. Am F Public Health 1983;73:1073-80.

12 Conseil des Affaires Sociales et de la Famille. Durée ou qualié de la vie? Québec: Les Publications du Québec, 1983.

13 Wilkins R, Sauvageau Y. Incapacité. In: Santé Québec, ed. Et la santé ça va? Rapport de l'enquête Santé Québec 1987. Vol 1. Quebec: Les Publications du Québec, 1988:175-92.

14 Robichaud JB. La santé des francophones. Moncton: Les Editions d'Acadie, 1985

15 Robine JM, Colvez A, Buquet D, Hatton F, Morel B, Lelaidier S. L'espérance de vie sans incapacité en France en 1982. Population 1986;6:1025-42.

16 Bebbington AC. The expectation of life without disability in England and Wales. Soc Sci Med 1988;27:321-6.

17 Crimmins EM, Saito Y, Ingegneri D. Changes in life expectancy and disability free life expectancy in the United States. Population and Development Review 1989;15:235-67.

18 Koizumi A. Health problems of the year 2000 and beyond. Health Policy $1985 ; 4: 307-19$

19 Katz S, Branch LG, Branson MH, Papsidero JA, Beck Jc, Greer DS. Active life expectancy. $N$ Engl F Med 1983;309:1218-24.

20 Rogers A, Rogers RG, Branch LG. A multistate analysis of active life expectancy. Public Health Rep 1989:104:222-6.

21 Robine JM, Brouard N, Colvez A. Les indicateurs d'espérance de vie sans incapacité(EVSI). Des indicateurs globaux de l'état de santé des populations. incapacite(EVSI). Des indicateurs globaux de

22 Manton KG. A longitudinal study of functional change and mortality in the United States. F Gerontol 1988;43:S153-61.

23 Davies M. Epidemiology and the challenge of ageing. Int $\mathcal{J}$ Epidemiol 1985;14:9-21.

24 World Health Organisation. International classification of impairments, disabilities and handicaps. Geneva: WHO, 1980.

25 Wood PN. Comment mesurer les conséquences de la maladie: la classification internationale des infirmités, incapacités et handicaps. Chronique OMS (Organisation Mondiale de la Santé) 1980;34:400-405.

26 Katz S, Akpom CA. A measure of primary sociological functions. Int 7 Healt Serv 1976;6:493-508.

27 Lawton MP, Brody AM. Assessment of older people: self-maintaining and instrumental activities of daily living. Gerontologist 1969;9:179-86.

28 Colvez A, Robine JM. Problems encountered in using the concepts of impairment, disability, and handicap in a health assessment survey of the elderly in Upper Normandy. International Rehabilitation Medicine 1986; 8:18-22.

29 Sturt E. Application of survival analysis to the inception of dementia. Psychol Med 1986;16:583-93.

30 Ritchie $\mathrm{K}$. The screening of cognitive impairment in the elderly: a critical review of current methods. J Clin Epidemiol 1988;41:635-43.

(Accepted 1 November 1990) 